\title{
Influence of clinical and demographic variables on quality of life in patients with Parkinson's disease
}

\author{
Karen Herlofson Karlsen, Jan P Larsen, Elise Tandberg, John G Mæland
}

\begin{abstract}
Objectives-To identify the clinical and demographic factors that are associated with a poor quality of life in patients with Parkinson's disease.

Methods-233 of a total of 245 patients identified in a community based study in a Norwegian county participated in the study. Quality of life was measured by the Nottingham Health Profile (NHP). The results were compared with those in 100 healthy elderly people. Clinical and demographic variables were determined during a semistructured interview and by clinical examination by a neurologist. Multiple regression analyses were used to determine which variables were associated with higher distress scores.
\end{abstract}

Results-Patients with Parkinson's disease had higher distress scores than the healthy elderly people for all the NHP dimensions. The variables that most strongly predicted a high total NHP score were depressive symptoms, self reported insomnia, and a low degree of independence, measured by the Schwab and England scale. Severity of parkinsonism contributed, but to a lesser extent. Nearly half the patients with Parkinson's disease reported lack of energy, compared with a fifth of the control group. Severity of depressive symptoms and a higher score on the UPDRS motor subscale only partly accounted for this finding. Only $30 \%$ of the variation in NHP energy score was explained by the predictive variables identified in this study.

Conclusions-Parkinson's disease has a substantial impact on health related quality of life. Depressive symptoms and sleep disorders correlated strongly with high distress scores. Patients with Parkinson's disease should be examined for both conditions, which require treatment. Low energy was commonly reported and may be a separate entity of Parkinson's disease.

(F Neurol Neurosurg Psychiatry 1999;66:431-435)

Keywords: Parkinson's disease; quality of life; multiple regression analysis

Professor Jan P Larsen, Department of Neurology, Central Hospital of Rogaland, PO Box 8100 , N-4003, Stavanger, Norway. Telephone 004751518450 ; fax 004751519916 .

Received 9 February 1998 and in revised form 1 September 1998

Accepted 11 September 1998

Medical treatment and management of patients with Parkinson's disease has concentrated on preserving normal life expectancy and limiting motor disabilities. The disease, however, also affects patients' health related quality of life in many other ways. ${ }^{1-4}$
The term health related quality of life describes distress and functional impairment that may be influenced by disease. There are many scales to measure different aspects of quality of life, both generic and disease specific. $^{56}$ The objective of most studies of quality of life in patients with Parkinson's disease has been to develop Parkinson's disease specific scales or to validate existing generic scales for this patient group..$^{7-9}$ Several recent studies of new medical treatments have also used one or more of these scales to evaluate the total impact of the new drugs on patients' wellbeing. ${ }^{10}$

The motor syndrome of parkinsonism has been expected to be the most important determinant of patients' distress, and management is primarily directed towards improving parkinsonian disability. This view was endorsed by Peto et $a l^{7}$ who found that tremor and stiffness were associated with lower quality of life, measured by the Parkinson's disease questionnaire (PDQ-39). Several other complaints related to Parkinson's disease such as depression, sleep disturbances, and side effects of drug therapy may increase the patients' distress; however, the effects of different clinical and demographic characteristics on health related quality of life in Parkinson's disease have not been adequately studied. A better understanding of what features of the disease have the greatest impact on the patients' wellbeing are important in developing new and improved management plans in Parkinson's disease.

The aim of the present study was to investigate the impact of different clinical features and demographic variables on the health related quality of life in Parkinson's disease, which was measured with the Nottingham Health Profile (NHP). ${ }^{11-13}$ We examined an unselected community based group of patients with Parkinson's disease and compared the level of distress among these patients with the quality of life measurements in a control group of healthy elderly people. Total NHP score and scores on the different quality of life dimensionsnamely, emotional reactions, energy, pain, physical mobility, sleep, and social isolationwere measured. We used multiple regression analysis to explore the predictive values of clinical and demographic variables that were likely to reduce quality of life.

\section{Patients and methods}

\section{PATIENTS}

This study was part of a prevalence study in the county of Rogaland, Norway. On 1 January 1993, the prevalence day, 245 patients were 
Table 1 Mean demographic and clinical data in 233 patients with Parkinson's disease

\begin{tabular}{ll}
\hline Age (y) & $73.6(8.4)$ \\
Sex (\% female) & 51 \\
Living alone (\%) & 39.2 \\
MADRS total score & $8.0(6.2)$ \\
Major depression (DSM III R) & $7.7 \%$ \\
MMSE total score & $24.4(6.9)$ \\
Nocturnal sleep disturbances (\%) & 60.3 \\
Duration of disease (y) & $6.3(5.3)$ \\
Daily levodopa dose (mg) & $496(233)$ \\
Side mostly affected (\%): & \\
Left & 38.9 \\
Right & 50.0 \\
Symmetric & 11.1 \\
Parkinson type (\%): & 11.4 \\
Tremor & 20.4 \\
Akinetic & 68.2 \\
Mixed & \\
UPDRS: & $49.3(26.2)$ \\
Total score & $3.8(2.8)$ \\
Part 1 score & $14.6(8.9)$ \\
Part 2 score & $28.4(15.8)$ \\
Part 3 score & $2.7(3.3)$ \\
Part 4 score & $2.9(1.1)$ \\
Hoehn and Yahr stage & $67.5(23.7)$ \\
Schwab and England score & $3.5(3.4)$ \\
Tremor score & $3.0(1.9)$ \\
Postural abnormalities score & $3.7(3.3)$ \\
Rigidity score & $11.0(6.5)$ \\
Akinesia score & 22.9 \\
Dyskinesias (\%) & 20.4 \\
Motor fluctuations (\%) & \\
Values in paren &
\end{tabular}

Values in parenthes are SD.

known to have Parkinson's disease. The prevalence rate was 110.9 per 100000 inhabitants. ${ }^{14}$ Patients living at home and in institutions were included and complete case ascertainment was attempted through an extensive search for patients known to the specialist neurological service, the general practitioners in the area, nursing homes, district nurses, and home health workers. The patients were diagnosed according to explicit diagnostic criteria. ${ }^{15}$ Two hundred and thirty three (115 men and 118 women) of the 245 patients were included in the quality of life study. Three patients died between the prevalence date and scheduled examination. Seven patients could not participate because of severe dementia and two patients refused to take part in the evaluation programme. Table 1 shows the characteristics of the patients. We also studied a control group of 100 healthy and well functioning elderly patients on routine visits to their general practitioners (GPs). They did not have disorders causing important disability, such as cancer and major cardiac disease. The control group had the same sex and age distribution as the patients with Parkinson's disease. The Norwegian ethics committee approved the study.

\section{EVALUATION PROGRAMME}

All patients were interviewed and examined between September 1992 and May 1993 in an evaluation programme consisting of two consecutive 1 hour consultations held within a month of one another. The quality of life questionnaire was given to the patients at the first consultation, completed at home, and returned at the second consultation. The patients in the control group were given the questionnaire at the GP clinic and they returned it by mail.

STUDY VARIABLES

We evaluated several possible prognostic variables for health related quality of life, both clinical and demographic. Parkinsonian disability was measured by the unified Parkinson's disease rating scale (UPDRS) including Hoehn and Yahr stage and Schwab and England scale. ${ }^{16-18}$ We used this scale to obtain scores for several clinical factors that we thought might have an impact on quality of life (table 1). We calculated a total tremor score by adding the scores on question 20 and 21 on the motor part of UPDRS (tremor at rest and action or postural tremor of hands). Rigidity was measured by the scores on question 22, akinesia by adding the scores on question 23, 24, 25, and 26 (finger taps, hand movements, and rapid alternating movements of hand, and leg agility). Postural abnormalities were measured by adding the scores for questions 29 and 30 (gait and postural stability). Dyskinesia and motor fluctuations were recorded as being present or not present. In addition we noted whether patients' symptoms were dominated by tremor, or akinesia, or were mixed; which side was most affected (left/right); duration of disease; daily levodopa dose; if the patient reported nocturnal sleep disturbances, and age, sex, and marital status. We also evaluated mental function (mini mental state examination, MMSE) ${ }^{19}$ and depression (DSM-III-R for major depression and the Montgomery and Åsberg depression rating scale, MADRS). ${ }^{2021}$ Table 1 lists the possible prognostic variables considered in this study.

Quality of life was measured with the Nottingham health profile (NHP) part 1, a generic, health related quality of life questionnaire. Part 1 of the NHP measures self assessed quality of life in six dimensions: emotional reactions, energy, pain, physical mobility, sleep, and social isolation. Respondents answer "yes" or "no" to a total of 38 questions. The answers are weighted: a score of 0 indicates no problems within an area and a score of 100 indicates all possible problems within an area. The NHP has been extensively tested for validity and reliability. ${ }^{11-13}$ The translation into Norwegian was done according to international principles.

\section{DATA ANALYSIS}

The results are presented as rates and proportions. Because of highly skewed distributions of the variables we used a non-parametric test (Mann-Whitney test) to compare the results from the two groups. We used Fisher's exact test to analyse frequency results. All the significance tests were two tailed. We used regression analysis (SPSS) to explore the association between the possible prognostic variables and reduced quality of life. It should be noted that we formally tested for normality applying Lilliefors test. This test showed that the standardised residuals deviations from normality were small. Taking into consideration our large data set, these deviations become negligible. In addition, we tested for interaction effects among explanatory variables that on theoretical grounds could contain such effects. These were between depression and physical impairment as measured by both Schwab and England and UPDRS motor, and depression 
Table 2 Mean NHP scores and percentage of patients reporting problems within each NHP dimension in patients with Parkinson's disease (PD) and elderly controls

\begin{tabular}{|c|c|c|c|c|c|c|c|c|c|c|c|c|c|c|}
\hline & \multicolumn{2}{|c|}{$\begin{array}{l}\text { Emotional } \\
\text { reactions }\end{array}$} & \multicolumn{2}{|l|}{ Energy } & \multicolumn{2}{|l|}{ Pain } & \multicolumn{2}{|c|}{ Physical mobility } & \multicolumn{2}{|l|}{ Sleep } & \multicolumn{2}{|c|}{ Social isolation } & \multicolumn{2}{|c|}{ Total NHP } \\
\hline & $\begin{array}{l}\text { Mean } \\
(S D)\end{array}$ & $\begin{array}{l}\% \\
\text { With } \\
\text { problems }\end{array}$ & $\begin{array}{l}\text { Mean } \\
(S D)\end{array}$ & $\begin{array}{l}\% \\
\text { With } \\
\text { problems }\end{array}$ & $\begin{array}{l}\text { Mean } \\
(S D)\end{array}$ & $\begin{array}{l}\% \\
\text { With } \\
\text { problems }\end{array}$ & $\begin{array}{l}\text { Mean } \\
(S D)\end{array}$ & $\begin{array}{l}\% \\
\text { With } \\
\text { problems }\end{array}$ & $\begin{array}{l}\text { Mean } \\
(S D)\end{array}$ & $\begin{array}{l}\% \\
\text { With } \\
\text { problems }\end{array}$ & $\begin{array}{l}\text { Mean } \\
(S D)\end{array}$ & $\begin{array}{l}\% \\
\text { With } \\
\text { problems }\end{array}$ & $\begin{array}{l}\text { Mean } \\
(S D)\end{array}$ & $\begin{array}{l}\% \\
\text { With } \\
\text { problems }\end{array}$ \\
\hline $\begin{array}{l}\text { Parkinson's } \\
\quad \text { disease } n=233\end{array}$ & $\begin{array}{l}13.1 \\
(17.0)\end{array}$ & 53 & $\begin{array}{l}26.3 \\
(33.3)\end{array}$ & 46 & $\begin{array}{l}22.0 \\
(24.6)\end{array}$ & 67 & $\begin{array}{l}41.2 \\
(31.7)\end{array}$ & 80 & $\begin{array}{l}27.2 \\
(28.4)\end{array}$ & 73 & $\begin{array}{l}20.4 \\
(23.6)\end{array}$ & 53 & $\begin{array}{l}137.1 \\
(97.3)\end{array}$ & 93 \\
\hline $\begin{array}{l}\text { Healthy elderly } \\
n=100\end{array}$ & $\begin{array}{l}6.3 \\
(13.5)\end{array}$ & 27 & $\begin{array}{l}10.0 \\
(21.2)\end{array}$ & 22 & $\begin{array}{l}13.5 \\
(22.5)\end{array}$ & 9 & $\begin{array}{l}11.1 \\
(16.2)\end{array}$ & 41 & $\begin{array}{l}19.4 \\
(28.4)\end{array}$ & 49 & $\begin{array}{l}10.8 \\
(17.6)\end{array}$ & 34 & $\begin{array}{l}67.6 \\
(83.7)\end{array}$ & 76 \\
\hline
\end{tabular}

Scores range from 0 indicating no problems to 100 indicating all possible problems within an area. All of the differences between the values of the two groups are significant at the $1 \%$ level $(\mathrm{p}<0.01)$, Mann-Whitney test.

and sleep disorders. None of these interaction effects were found significant at the $5 \%$ level.

\section{Results}

DESCRIPTIVE DATA

The mean age in the patient population was 73.6 (SD 8.4) years, in the control group 72.8 (SD 8.2) years. In both groups there was an equal distribution between men and women. For all the dimensions measured with NHP patients with Parkinson's disease had a lower quality of life, reflected by higher scores, than the healthy elderly people. Patients with Parkinson's disease had the highest score in the dimension of physical mobility, but the dimensions of sleep and energy also received high distress scores. The mean total NHP score for patients with Parkinson's disease was 137, compared with 68 for the healthy elderly group (table 2).

MULTIPLE REGRESSION ANALYSIS

Because the possible predictive clinical and demographic variables for decreased quality of life may be interrelated, with ample room for confounding, we analysed the data by use of multiple regression analyses. Table 1 lists the variables presumed to affect health related quality of life and which were included in the

Table 3 Correlation of clinical factors with NHP total score and the NHP subdimensions. Regression coefficients, standard error (SEM), $t$ values, $p$ values, and adjusted $R^{2}$

\begin{tabular}{|c|c|c|c|c|c|c|}
\hline Variable & $\begin{array}{l}\text { Univariate } \\
\text { regr coeff }\end{array}$ & $\begin{array}{l}\text { Multivariate } \\
\text { regr coeff }\end{array}$ & SEM & $t$ Value & $p$ Value & $\begin{array}{l}\text { Adjusted } \\
R^{2}\end{array}$ \\
\hline \multicolumn{7}{|l|}{ NHP total score: } \\
\hline MADRS score & 10.06 & 5.23 & 0.95 & 5.53 & 0.000 & \multirow[t]{5}{*}{0.54} \\
\hline Sleep disorders & 55.30 & 65.6 & & 6.33 & 0.000 & \\
\hline Schwab and England & -2.76 & -1.95 & 0.27 & -7.24 & 0.000 & \\
\hline UPDRS motor & 3.60 & 1.63 & 0.78 & 2.10 & 0.037 & \\
\hline Levodopa dose & 0.13 & 0.07 & 0.02 & 3.47 & 0.001 & \\
\hline \multicolumn{7}{|l|}{ Emotional disorders: } \\
\hline MADRS score & 1.44 & 1.35 & 0.16 & 0.50 & 0.000 & 0.28 \\
\hline \multicolumn{7}{|l|}{ Energy: } \\
\hline MADRS score & 2.78 & 2.27 & 0.33 & 6.89 & 0.000 & \multirow[t]{3}{*}{0.30} \\
\hline UPDRS motor & 0.81 & 0.39 & 0.15 & 2.68 & 0.008 & \\
\hline Levodopa dose & 0.03 & 0.02 & 0.01 & 2.13 & 0.034 & \\
\hline \multicolumn{7}{|l|}{ Pain: } \\
\hline MADRS score & 1.04 & 1.14 & 0.29 & 3.98 & 0.000 & \multirow[t]{3}{*}{0.17} \\
\hline Hoehn and Yahr score & 0.74 & 0.63 & 0.16 & 3.93 & 0.000 & \\
\hline Major depression & 7.04 & 24.47 & & 3.79 & 0.000 & \\
\hline \multicolumn{7}{|l|}{ Physical mobility: } \\
\hline Schwab and England & -1.07 & -0.96 & 0.07 & -13.1 & 0.000 & \multirow[t]{4}{*}{0.57} \\
\hline Age & 1.68 & 0.50 & 0.19 & 2.57 & 0.011 & \\
\hline Sleep disorders & 4.25 & 8.35 & & 2.95 & 0.004 & \\
\hline Levodopa dose & 0.02 & 0.01 & 0.01 & 2.14 & 0.034 & \\
\hline \multicolumn{7}{|l|}{ Sleep: } \\
\hline Sleep disorders & 31.52 & 36.3 & & 12.2 & 0.000 & \multirow{2}{*}{0.42} \\
\hline Levodopa dose & 0.02 & 0.01 & 0.01 & 2.34 & 0.020 & \\
\hline \multicolumn{7}{|l|}{ Social isolation: } \\
\hline MADRS score & 1.79 & 1.19 & 0.22 & 5.36 & 0.000 & \multirow{3}{*}{0.34} \\
\hline Hoehn and Yahr stage & 1.09 & 0.81 & 0.14 & 5.95 & 0.000 & \\
\hline Sleep disorders & 8.09 & 7.24 & & 2.75 & 0.006 & \\
\hline
\end{tabular}

analyses as independent variables. As dependent variables we entered NHP total score as well as all six dimensions of the NHP separately.

Table 3 shows that depressive symptoms, sleep problems, and low Schwab and England score were the variables that had the most detrimental effect on overall quality of life, measured by total NHP score. Higher levodopa dose also contributed to the model $(\mathrm{p}<0.05)$. The full model explained $54 \%$ of the variance of the total NHP score (adjusted $R^{2}$ ).

The subscore for emotional reactions in the NHP correlated strongly with MADRS score; no other variable was included at the $5 \%$ level of significance. The model explained $28 \%$ of the variance of the NHP emotional reactions score.

Problems of low energy were mostly affected by degree of depressive symptoms, but also higher levodopa dose and a higher score on the UPDRS motor scale contributed to a higher distress score. The model explained $30 \%$ of the variance of the NHP energy score.

Higher score in the dimension of pain was predicted by the degree of depressive symptoms and more advanced disease as measured by higher Hoehn and Yahr stage. The full model did, however, only explain $17 \%$ of the variance in the NHP pain score.

Fifty seven per cent of the variance of the score in the dimension of physical mobility could be explained by Schwab and England score, age, sleep problems, and higher levodopa dose.

The sleep dimension of the NHP correlated strongly with self reported nocturnal sleep disturbances and in addition a high levodopa dose contributed to the predictive power of the model.

The factors that contributed most to higher degree of social isolation were depressive symptoms, higher Hoehn and Yahr stage, and sleep disturbances.

\section{Discussion}

This study showed that Parkinson's disease affects health related quality of life and that patients with Parkinson's disease had higher levels of distress than healthy elderly people in all the dimensions measured by the NHP. The clinical factors that showed the highest predictive value for total NHP score among the patients with Parkinson's disease were depression measured by MADRS, sleep disorders, and a low degree of independence (measured 
by the Schwab and England scale). Severity of parkinsonism contributed to a lesser extent to the patients' self reported distress. These results have important implications for the optimal management of patients with Parkinson's disease.

Quality of life measurements are increasingly used to evaluate medical treatment and total patient management. ${ }^{1022}{ }^{23}$ However, a lack of agreement on the definition of quality of life means that a wide range of quality of life profiles and indices are used to assess health related distress. Such variety has complicated the validation and comparison of findings. The scales that measure different aspects of health or quality of life can be divided into those based on observation or examination by trained health personnel and those based on the patient's self assessed quality of life. Self assessment is generally used in clinical and epidemiological work, and the previously published studies describing quality of life in patients with Parkinson's disease all used this approach. We chose the NHP because it measures aspects of quality of life that are relevant to patients with Parkinson's disease. In addition it has undergone rigorous testing for reliability and validity and it is easy to administer, understand, and answer. The NHP was also used in the large study of Sinemet CR in early Parkinson's disease. ${ }^{10}$ Because the NHP was developed to measure effects on quality of life at the severe end of ill health a limitation is that the results may be highly skewed in many patient groups and that small improvements may not be detected.

Most earlier studies describing quality of life in patients with Parkinson's disease have been performed to develop or validate methods of measuring the patients' health related distress. These studies have not been designed to describe quality of life in the general Parkinson's disease population or to examine the predictive value of different Parkinson's disease related clinical and demographic factors for self reported distress. None the less, these earlier studies confirm that Parkinson's disease has an important impact on the patients' life, and that this influence may originate from several different aspects of the disease. Unlike the previous studies we set out to examine health related quality of life in an unselected group of patients with Parkinson's disease. We studied the patients recruited from a communitybased prevalence study, ${ }^{14}$ and the high rate of participation in this study (233 of the 245 patients) suggests that the performed analyses should provide valid information on the health related quality of life of patients with Parkinson's disease.

The mean age of the patients reflects an older patient population than is seen in hospital based studies, and a higher degree of other diseases at this higher age would be expected. It is entirely possible that concomitant diseases might also have influenced motor function. The control group consisted of 100 elderly subjects. We did not include patients with cancer or major cardiac disease. Because the prevalence of these diseases is the same in patients with Parkinson's disease as in the general population, this limits the comparability of the groups, and accentuates the differences between the patient group and the control group. The controls were not evaluated in an identical way to the parkinsonian patients and it is possible that this may have influenced the results. Both the patient and the control group did, however, complete the quality of life questionnaire independently at home.

The physical disability caused by Parkinson's disease has traditionally been regarded as the most important feature of the disease that causes distress, and it has received the most attention in the management of patients with Parkinson's disease. In our unselected patients with Parkinson's disease we found that increased physical disability made only a small contribution to the decrease in the health related quality of life. This does not accord with the results of a study by Peto $e t ~ a l,{ }^{7}$ which showed that tremor and rigidity correlated strongly with a higher distress score. This may be because the variables are highly intercorrelated and the results of Peto et al were based on univariate analyses. We wanted to identify the prognostic value of several different factors so we adjusted for such intercorrelations by using multiple regression analyses. We do, however, also report the univariate regression coefficients of those variables that contributed significantly to the multivariate model. This shows that there was a tendency towards higher regression coefficients for depressive symptoms and sleep disorders in the multivariate model; all the other variables showed slightly lower values.

Depression and the presence of sleep disorders explained the largest part of the higher level of distress. Earlier studies of the same patient population showed that depression was common in Parkinson's disease. Tandberg et $a l^{4}$ found that $5.1 \%$ of the patients had major depression and that $45.5 \%$ had had milder depressive symptoms. The importance of depression in Parkinson's disease has also been shown in several other studies. ${ }^{25}$ This underlines the importance of diagnosing depressive symptoms in patients with Parkinson's disease and treating them when appropriate.

Earlier studies have shown that many patients with Parkinson's disease complain of sleep disorders. ${ }^{26}{ }^{27}$ Early and frequent wakening, cramps, pains, and nightmares are common at night. Our results show that these complaints had an important impact on patients' quality of life, and were more predictive of distress than increased physical disability. A higher mean levodopa dose showed a small, but significant association with lower quality of life. It is, however, not clear if this association was due to levodopa itself, or a reflection of the probability that higher levodopa doses are given to patients with a more advanced disease.

The NHP part 1 examines different dimensions of quality of life. In the dimension of emotional reactions patients with Parkinson's disease scored higher (worse) than the healthy elderly group. In the multiple regression analysis the only variable that showed a strong correlation with a high score in this dimension was the MADRS score. This shows that there is 
good correlation between depressive symptoms assessed by physicians and the patients' self reported emotional distress.

In the dimension of physical mobility patients with Parkinson's disease had, as expected, much higher scores than the healthy elderly people. Disease specific scales are, however, more likely to give a more comprehensive picture of disability than $\mathrm{NHP} .{ }^{28}$ Over two thirds of the patients in our study reported problems caused by pain. This result can probably be ascribed both to parkinsonism itself and to the increasing secondary muscle stiffness of advanced Parkinson's disease. The multiple regression analysis showed that as well as advanced Parkinson's disease, depressive symptoms predicted a higher pain score. Again, this emphasises the importance of diagnosing and treating depression in patients with Parkinson's disease.

Nearly half the patients in our study reported lack of energy, and the score in this dimension was much higher than for the healthy elderly people. The rating scales normally used to assess patients with Parkinson's disease are not designed to uncover this important finding. Multiple regression analysis showed that depression may account for some of the variance in the NHP score, but also that a higher score on the UPDRS motor subscale had predictive value. It has previously been claimed that fatigue is an independent symptom of Parkinson's disease and that it is not solely the result of disability, insomnia, depression, or other well recognised features of the disease. ${ }^{29}$ Our results show that complaints of low energy can only partly be explained by the other features of the disease and thus indicate that fatigue may be a symptom of the cerebral pathological process of Parkinson's disease. This possibility needs to be explored further.

This study shows that Parkinson's disease has a substantial impact on health related quality of life. Patients with Parkinson's disease had higher distress scores, not only for the obvious dimensions of physical mobility and emotional reactions, but they also reported more pain, less energy, more social isolation, and more sleep disorders than healthy elderly people. Multiple regression analysis showed that depressive symptoms, presence of sleep disorders, and low degree of independence were the variables that most strongly predicted the total NHP score. We also showed that low energy was commonly reported by patients with Parkinson's disease and that this complaint could be a manifestation of Parkinson's disease itself. The realisation that Parkinson's disease affects patients' lives in many areas other than physical disability enhances our ability to detect and treat these symptoms and to develop new treatments aimed at improving all aspects of Parkinson's disease and thus giving these patients as good a quality of life as possible.
We thank Assistant Professor Kjell Jørgensen, Norwegian School of Management, for his work with the statistical analyses.

1 Shindler J, Brown R, Welburn P, et al. Measuring the quality of life of patients with Parkinson's disease. In: Walker S, of life of patients with Parkinson's disease. In: Walker S,
Rosser R, eds. Quality of life: assessment and applications. Rosser R, eds. Quality of life:

2 Welburn P, Walker S. Assessment of quality of life in Parkinson's disease. In: Teeling Smith G, ed. Measuring health: a practical approach. Chichester, Wiley, 1988.

3 Mutch WJ, Strudwick A, Roy SK, et al. Parkinson's disease: disability, review, and management. BMF 1986;239:675-7.

4 Jenkinson C, Peto V, Fitzpatrick R, et al. Self-reported functioning and well-being in patients with Parkinson's disease: comparison of the short-form health survey (SF-36) and the Parkinson's disease questionnaire (PDQ-39). Age Ageing 1995;24:505-9.

5 Jenkinson C, Fitzpatrick R, Argyle M. The Nottingham health profile: an analysis of its sensitivity in differentiating illness groups. Soc Sci Med 1988;27:1411-4.

6 Bergner M, Bobbitt RA, Carter WB, et al. The sickness impact profile: development and final revision of a health status measure. Med Care 1981;19:787-805.

7 Peto V, Jenkinson C, Fitzpatrick R, et al. The development and validation of a short measure of functioning and well being for individuals with Parkinson's disease. Qual Life Res 1995;4:241-8.

8 de Boer AGEM, Wijker W, Speelman JD, et al. Quality of life in patients with Parkinson's disease: development of a questionnaire. F Neurol Neurosurg Psychiatry 1996;61:70-4.

9 Longstreth WT Jr, Nelson L, Linde M, et al. Utility of the sickness impact profile in Parkinson' disease. F Geriatr Psychiatry Neurol 1992;5:142-8.

10 Block G, Liss C, Reines S, et al. Comparison of immediaterelease and controlled release carbidopa/levodopa in Parkinson's disease. Eur Neurol 1997;37:23-7.

11 Hunt SM, McKenna SP, McEwen J, et al. The Nottingham health profile: subjective health status and medical consultations. Soc Sci Med 1981;15A:221-9.

12 Hunt SM, McEwen J, McKenna SP. Measuring health status: a new tool for clinicians and epidemiologists. $\mathcal{F}$ Coll Gen Pract 1985;35:185-88.

13 Hunt SM, McEwen J, McKenna SP. Measuring health status. London: Croom Helm, 1986.

14 Tandberg E, Larsen JP, Nessler EG, et al. The epidemiology of Parkinson's disease in the county of Rogaland, Norway. Mov Disord 1995;10:541-9.

15 Larsen JP, Dupont E, Tandberg E. The clinical diagnosis of Parkinson's disease: proposal of diagnostic subgroups clas-
sified at different levels of confidence. Acta Neurol Scand 1994;84:242-51.

16 Fahn S, Elton RL and members of the UPDRS Development Committee. Unified Parkinson's disease rating scale. In: Fahn S, Marsden CD, Calne DB, et al, eds. Recent developments in Parkinson's disease. Florham Park, NJ: MacMillan Health Care Information, 1987:153-63.

17 Hoehn M, Yahr M. Parkinsonism: onset, progression and mortality. Neurology 1967;17:427-42.

18 Schwab RS, England AC. Projection technique for evaluating surgery in Parkinson's disease. In: Gillingham FJ, Don-
aldson IML, eds. Third symposium on Parkinson's disease. Edinburgh: E and S Livingstone, 1969.

19 Folstein MF, Folstein SE, McHugh PR. Mini-mental state: a practical method for grading the mental state of patients for the clinicians. F Psychiatr Res 1975;12:189-98.

20 American Psychiatric Association. Diagnostic and statistical manual of mental disorders. Washington, DC: APA, 1987.

21 Montgomery SA, Åsberg M. A new depression scale designed to be sensitive to change. $B r \mathcal{F}$ Psychiatry 1979;134:322-89.

22 Dornan TL, Peck GM, Dow JDC, et al. A community survey of diabetes in the elderly. Diabet Med 1992;9:860-5.

23 Essink-Bot ML, van Royen L, Krabbe P, et al. The impact of migraine on health status. Headache 1995;35:200-6.

24 Tandberg E, Larsen JP, Aarsland D, et al. The occurrence of depression in Parkinson's disease: a community-based study. Arch Neurol 1996;53:175-9.

25 Cummings JL. Depression and Parkinsons' disease: a review. Am f Psychiatry 1992;149:443-54.

26 Lees AJ, Blackburn NA, Campell VL. The nighttime problems of Parkinson's disease. Clin Neuropharmacol 1988;6: 512-9.

27 Nausieda PA, Weiner WJ, Kaplan LR, et al. Sleep disruption in the chronic levodopa therapy: an early feature of the levodopa psychosis. Clin Neuropharmacol 1982;2:183-94.

28 Hendersen L, Kennard C, Crawford T. Scales for rating motor impairment in Parkinson's disease: studies of reliability and convergent validity. $\mathcal{f}$ Neurol Neurosurg Psychiatry 1991;54:18-24.

29 Friedman J, Friedman H. Fatigue in Parkinson's disease. Neurology 1993;43:2016-8. 